\title{
Final height in boys with untreated constitutional delay in growth and puberty
}

\author{
E C Crowne, S M Shalet, W H B Wallace, D M Eminson, D A Price
}

\begin{abstract}
To determine the natural history and psychological impact of the growth pattern in boys with constitutional delay in growth and puberty (CDGP), 43 boys presenting with short stature due to CDGP were followed up to final height. At presentation mean (SD) chronological age was $14.0(1.9)$ years, bone age delay $2.7(1.0)$ years, standing height standard deviation score (SDS) $-3.4(0.6)$, and predicted adult height SDS $-1.3(0.7)$. Final adult height SDS was $-1.6(0.9)$, measured at $21.2(2.6)$ years. There was no significant difference between final height and predicted adult height, but there was a significant difference between final height and measured mid-parental height.

Psychological questionnaires showed no significant difference in self esteem, marital, or employment state between the CDGP group and a control group. There was no correlation between self esteem and final height, but 25 felt their growth delay had affected their success either at school, work, or socially and 20 would rather have had treatment to advance their growth spurt.

This study supports the more frequent use of active medical treatment to advance growth in boys with CDGP, and shows that although boys with CDGP reach their predicted heights, this is short for their families.
\end{abstract}

Short stature due to constitutional delay in growth and puberty (CDGP) is commonly seen in paediatric practice, and although an extreme of normal development rather than a clinical disorder, can still pose considerable clinical problems. There is a significant number of patients who remain unhappy despite explanation of the diagnosis and promise of normal growth to come and eventual normal final adult height when growth is finished. In this group psychological distress may affect behaviour and school performance and according to some authors persists into adult life. ${ }^{1-3}$ Hence the use of pharmacological treatments to improve short term growth and allow the patients, usually adolescent boys, to keep pace with their peers. ${ }^{4-8}$ Assessment of growth and psychological responses to treatments such as low dose testosterone, oxandrolone, and especially growth hormone requires knowledge of the natural history and outcome of untreated CDGP. We have therefore reviewed the growth and psychological wellbeing of boys with CDGP seen in growth and endocrine clinics between 1976 and 1986 who did not receive hormonal treatment and who have now reached their final height.

\section{Patients and methods}

The records of 118 boys seen between 1976 and 1986 with short stature due to CDGP were reviewed. The boys had all had CDGP diagnosed when first seen. Five had attended clinic until reaching their final height. The remaining 113 were contacted by letter: 38 replied and agreed to come back to clinic, two refused to return, 15 letters were returned as the families had moved, and 58 remained unanswered. The 38 responders returned to clinic for measurement and to complete a psychological questionnaire. The $\mathbf{4 3}$ patients followed up to final adult height fulfilled the following criteria at presentation:

(1) Short stature (height less than 2 SD below the mean).

(2) Delayed puberty (onset delayed by more than 2 SD-that is, had not achieved $4 \mathrm{ml}$ testes until aged 14 years)

(3) Bone age below the 10th centile for chronological age (delayed by more than 1.5 years).

(4) No clinical evidence of chronic disease or endocrinopathy.

They were considered to be at their final adult height if growing less than $2 \mathrm{~cm} /$ year or aged more than 21 years. All had completed normal pubertal development. Standing and sitting height measurements were performed using a fixed Harpenden stadiometer and subischial leg length was obtained by subtracting sitting height from standing height. Standard deviation scores (SDS) were calculated using published tables. ${ }^{9}$ Pubertal stage was assessed according to the method of Tanner and Whitehouse. ${ }^{10}$

Chronological age, height, and pubertal stage at presentation were obtained from the notes both of those measured to final height (group A) and a randomly selected sample of those whom we had not traced (group $\mathbf{B}, \mathbf{n}=33$ ) in order to ensure that those who responded positively were truly representative of the whole cohort of boys with CDGP. The bone ages were assessed according to the method of Tanner and Whitehouse by one observer (ECC) and predicted adult height estimated using the TannerWhitehouse II method. ${ }^{11}$ Mid-parental height was obtained using reported parental heights (the mean of father's height and mother's height plus $12.5 \mathrm{~cm}$ ). Target genetic height is defined as the mid-parental height $\pm 8.5 \mathrm{~cm}$ and represents the range of heights likely to be achieved by $95 \%$ of a couple's sons. In a subset $(n=40)$ parental heights were checked using a portable microtoise stadiometer.

To assess self esteem and social function, questionnaires were administered. These consisted of the adult Coopersmith self esteem
Wilmslow Road, Didsbury, Manchester M20 9BX.

Accepted 8 June 1990 
inventory, ${ }^{12}$ and a questionnaire asking specifically about current attitudes to height, current social and employment history, what problems, if any, they attributed to their growth delay and, if in retrospect they would rather have had treatment. The results of these questionnaires were compared with those of a group of 43 normal young men of the same age range and living in the same area who were drawn from hospital employees and their families. This group was chosen rather than a student population as being more comparable in social activity. There was no significant difference in social class between the control and study group but the groups were not matched for height, the control group being significantly taller (height SDS 0.47 (1.05) (reported height) compared with $-1.6(0.9), \mathrm{p}<0.001)$.

Table 1 Growth data at presentation of boys with CDGP. Results are mean $(S D)$

\begin{tabular}{lcc}
\hline Data at presentation & $\begin{array}{l}\text { Group } A \\
(n=43)\end{array}$ & $\begin{array}{l}\text { Group } B \\
(n=33)\end{array}$ \\
\hline Age (years) & $14 \cdot 0(1 \cdot 9)$ & $14 \cdot 1(1 \cdot 9)$ \\
Bone age (years) & $11 \cdot 3(2 \cdot 5)$ & $11 \cdot 4(2 \cdot 1)$ \\
Bone age delay (years) & $2 \cdot 7(1 \cdot 0)$ & $2 \cdot 8(0 \cdot 8)$ \\
Standing height (cm) & $139 \cdot 0(11 \cdot 4)$ & $141 \cdot 6(10 \cdot 4)$ \\
Standing height SDS & $-3 \cdot 4(0 \cdot 6)$ & $-3 \cdot 0(0 \cdot 9)$ \\
Mid-parental height (cm) & $170 \cdot 6(4 \cdot 8)$ & $171 \cdot 5(5 \cdot 9)$ \\
Mid-parental height SDS & $-0.6(0 \cdot 7)$ & $-0.5(0 \cdot 9)$ \\
Predicted adult height (cm) & $166 \cdot 1(4 \cdot 6)$ & $167 \cdot 2(3 \cdot 9)$ \\
Predicted adult height SDS & $-1.3(0 \cdot 7)$ & $-1 \cdot 2(0 \cdot 5)$ \\
\hline
\end{tabular}

Table 2 Data at final height of 43 boys with CDGP. Results are mean $(S D)$

\begin{tabular}{lr}
\hline Data at final adult height & \\
\hline Age (years) & $21 \cdot 2(2 \cdot 6)$ \\
Standing height (cm) & $164 \cdot 1(6 \cdot 0)$ \\
Standing height SDS & $-1.6(0 \cdot 9)$ \\
Sitting height (cm) & $87 \cdot 8(3 \cdot 1)$ \\
Sitting height SDS & $-1 \cdot 7(1 \cdot 0)$ \\
Leg length (cm) & $76 \cdot 1(3.9)$ \\
Leg length SDS & $-1 \cdot 2(0.9)$ \\
Leg length SDS minus sitting height SDS & $0.5(0 \cdot 9)$ \\
Change in height SDS & $1 \cdot 8(0 \cdot 8)$ \\
Final height minus predicted adult height (cm) & $-2 \cdot 0(4 \cdot 5)$ \\
Final height minus mid-parental height (cm) & $-6.5(6.0)$ \\
\hline
\end{tabular}

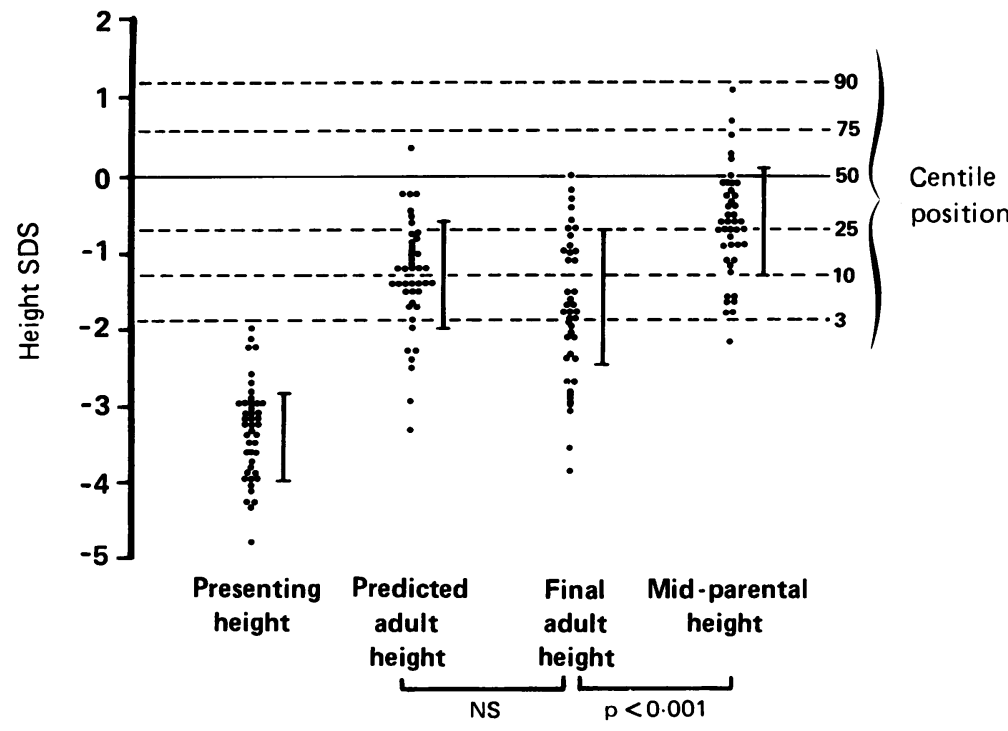

Presenting height, predicted adult height, final height, and mid-parental height SDS for 43 boys with constitutional delay in growth and puberty.
Results were expressed as mean (SD). Statistical analyses were performed using the MannWhitney $U$ test and Student's paired and unpaired $t$ test.

\section{Results}

Comparison of the data at presentation between groups A and B (table 1) shows no significant differences in chronological age, bone age delay, standing height, mid-parental height, or predicted adult height between those whom we were able to trace and follow up to final height and those who were lost to follow up.

\section{GROUP A: GROWTH DATA}

For those followed up to final height there was a significant improvement in height SDS $(-3.4$ $(0.6)$ to $-1.6(0.9), p<0.001)$ (table 2). Final height was above the third centile in $32(74 \%)$, and above the 10th centile in 20 (47\%) (figure). There was no correlation between final height and social class.

\section{(1) Comparison of final adult height and predicted} adult height (figure)

There was no significant difference between final height and predicted adult height (SDS $-1.6(0.9)$ compared with $-1.3(0.7))$. The mean difference was $-2.00(4.5) \mathrm{cm}$. In seven boys (16\%), the final height was more than $5 \mathrm{~cm}$ below the predicted adult height, and in two (5\%), more than $5 \mathrm{~cm}$ above the predicted adult height. There was no correlation between the accuracy of the height prediction and chronological age, height, or bone age at presentation but there was a significant correlation with bone age delay at presentation $(p<0.001)$ so that the greater the bone age delay the less accurate the height prediction proved to be.

(2) Comparison of final adult height and midparental height (figure)

There was a significant difference between final height and mid-parental height $(\mathrm{p}<0.001)$, with a mean difference of $-6.5(6.0) \mathrm{cm}$. The reliability of reported heights is suspect, and in fact there was a significant difference between the reported and measured mid-parental heights (170.9 (4.9) compared with $168.3(4 \cdot 1)$, $p=0.03)$. In 14 of the 20 sets of parents measured this difference was less than $1 \mathrm{~cm}$. In the remaining six couples (32\%) the difference was greater than $2.5 \mathrm{~cm}$. Four couples overestimated and two couples underestimated their height. The difference between final height and measured mid-parental height was still significant in this subgroup ( $p=0 \cdot 003)$.

(3) Comparison of sitting height and leg length To look for disproportion, leg length SDS minus sitting height SDS was calculated and was within $2 \mathrm{SD}$ of the mean in all cases. There was, however, a significant difference between leg length SDS and sitting height SDS $(p=0.03)$, with a mean difference of $0.5(0.9)$. There was 
Table 3 Replies to psychological questionnaires

\begin{tabular}{|c|c|c|}
\hline \multirow[t]{2}{*}{ Question } & \multicolumn{2}{|c|}{ No (\%) replying yes } \\
\hline & $\begin{array}{l}C D G P \\
(n=38)\end{array}$ & $\begin{array}{l}\text { Normals } \\
(n=43)\end{array}$ \\
\hline $\begin{array}{l}\text { Are you satisfied with your height? } \\
\text { Would you like to be a different height? } \\
\text { Do you think your height interfered with your success at } \\
\text { school/work/socially/sports? } \\
\text { Did coming to the clinic make you feel better? } \\
\text { Did coming to the clinic make you grow better? } \\
\text { Would you rather have had treatment to make you grow sooner } \\
\text { even if you ended up the same height? } \\
\text { If you had children with delay in their growth, would you want } \\
\text { treatment to make them grow sooner? }\end{array}$ & $\begin{array}{r}30(79) \\
23(60) \\
25(65) \\
22(57) \\
6(15) \\
20(53) \\
21(55)\end{array}$ & $\begin{array}{l}42(98) \\
2(5) \\
7(16) \\
- \\
- \\
-\end{array}$ \\
\hline
\end{tabular}

no significant correlation between bone age delay at presentation and the difference between adult leg length SDS and sitting height SDS.

\section{QUESTIONNAIRE MEASURES}

There was no significant difference in self esteem, measured by the Coopersmith self esteem inventory, between the boys with CDGP and the normal group $(77.6(14.8)$ and 76.8 (12.9) respectively). Neither did they differ in social activity applying the scoring system used to assess their social lives. There was no significant correlation between their self esteem score and any of the following variables: social class, final adult height achieved, gain in height since presentation, bone age delay at presentation, and the shortfall between achieved adult height and either mid-parental height or predicted adult height. There was no significant correlation between self esteem and social activity.

There was no significant difference between the number married or in stable relationships between the two groups ( 35 in the CDGP group and 31 in the normals) or in the number unemployed (one and two respectively).

The replies to the questionnaire about attitudes to height are shown in table 3. Eighteen said they no longer thought about their height at all, a further 17 only occasionally. Thirty of the CDGP group were satisfied with their final height as compared with all but one of the normals, this despite the fact that the CDGP group were significantly shorter than the controls. A total of 23 , however, did want to be a different height, that is, taller, compared with only two of the controls. Twenty five thought their height had interfered with success-in everything $(n=3)$, socially $(n=13)$, at school because of teasing $(n=9)$, and in sport $(n=9)$. Eight did not remember being worried themselves about their height. Attendance at a clinic had made 22 of the boys feel better and six thought it had made them grow better. Even though most were now happy about their height, 20 would rather have had treatment to bring forward their growth spurt and 21 wanted such treatment available for their children if faced with a similar growth problem.

\section{Discussion}

This study illustrates the difficulties inherent in following up boys with CDGP to final height, and may well account for the paucity of data on its untreated course. By the nature of the condition, the boys are not ill, have not received treatment, and once they have started their pubertal growth and development, not unnaturally, usually prefer to leave the clinic. This age group are also mobile geographically and can be difficult to trace retrospectively. Our sample, although only $37 \%$ of the full cohort, did not differ significantly from the remainder in any of their presenting features. There is therefore no obvious bias in selection and their growth pattern should be representative of the group as a whole.

The boys showed a significant improvement in height SDS, as expected in a condition where growth is merely delayed. The majority achieved their predicted height, although there was a significant number $(21 \%)$ where the prediction differed by more than $5 \mathrm{~cm}$. This is in agreement with recent reports of final height in smaller numbers of boys with untreated CDGP. ${ }^{13} 14$ Our results indicate, however, that although most boys reach their target genetic height, as a group they are significantly shorter than their mid-parental heights. This was also shown by LaFranchi et al, although they used reported parental heights only. ${ }^{13} \mathrm{We}$ were able to measure a subset of parents, and although a significant difference between reported and measured heights was found, the sons were still significantly short in the context of their parental heights. These results need to be taken into consideration when assessing the need for active treatment, particularly in boys with short parents, but also when analysing the outcome of hormone or drug treatment on final height in boys with CDGP.

Although there was a significant difference between leg length SDS and sitting height SDS (mean 0.5 (0.9)) this does not mean there was a significant disproportion at final adult height. This discrepancy has also been noted in other groups of children in whom disproportion would not be expected, ${ }^{15}$ and may simply reflect the difference in sitting height measurement using the Harpenden stadiometer as the original SDS tables were constructed using measurements from an anthropometer.

At present the principal reason for treating boys with CDGP with growth promoting agents is to alleviate the short term distress caused by the discrepancy in development in comparison with their peers. Poor achievement in education has been found to correlate with late maturation in boys in a study that controlled for intellectual abilities. ${ }^{16}$ In addition, impressionistic studies indicate that the adverse psychological impact may persist into adult life. ${ }^{3}$ We found no significant difference in self esteem, marital, or employment state between our study group and the controls. It must also be stressed that there are individual differences because of 'a complex interplay of factors' so that the response of any individual to late development will be modified by other physical, psychological, or social factors. Although these young men had normal self esteem and social functioning, $60 \%$ did want to be taller than their achieved final height. The majority $(79 \%)$, however, were satisfied with their eventual height and no longer regarded it 
as a problem. Furthermore as there was no correlation between self esteem and final height achieved, this would argue against the need for treatment for the majority designed to actually improve final height.

On the other hand, the young men also recalled the difficulties their short stature had caused them. A half felt it had affected their success especially at school and socially. Furthermore, half felt that in retrospect they would have liked treatment to advance their growth spurt, and $55 \%$ wanted the availability of such treatment for any of their children faced with the same growth problem. These results support the notion of both hormonal and psychological intervention at the time of presentation to treat and prevent distress at that time.

In conclusion, therefore, our results demonstrate the expected improvement in growth rate in boys with CDGP, but suggest that they do not in fact achieve their full genetic potential. We did not demonstrate a link with poor self esteem or reduced social activity, but although the boys were past their growth problems, there was retrospective evidence of significant psychological distress in adolescence and a strong desire from the boys themselves for active treatment, although attendance at clinic had provided some reassurance. Remaining problems include the definition of criteria to be used in determining which boys with CDGP should be treated, and the development of suitable methods of assessment of the impact of such treatments on their psychological well being. Prospective randomised trails are necessary to address these points.
We are grateful for the support of Genentech during the study.

1 Mussen PH, Jones MC. Self conceptions, motivations and interpersonal attitudes of late and early maturing boys. Child Dev 1957;28:243-56.

2 Gordon M, Crouthamel C, Post EM, Richman RA. Psychosocial aspects of constitutional short stature: social competence, behaviour problems, self-esteem and family functioning. F Pediatr 1982;101:477-80.

3 Jones MC. The late careers of boys who were early- or latematuring. Child Dev 1957;28:113-28.

4 Shalet SM. Treatment of constitutional delay in growth and puberty (CDGP). Clin Endocrinol (Oxf 1989;31:81-6.

5 Martin MM, Martin ALA, Mossman KL. Testosterone treatment of constitutional delay in growth and developtreatment of constitutional delay in growth and development: effect of dose on predicted versus definitive height
Acta Endocrinol [Suppl] (Copenh) 1986;279:147-52.

6 Stanhope R, Brook CGD. Oxandrolone in low dose for constitutional delay of growth and puberty in boys. Arch
cher Dis Child 1985;60:379-81.

7 Bierich JR. Treatment of constitutional delay of growth and adolescence with human growth hormone. Klin Padiatr 1983;195:309-16.

8 Richman RA, Kirsch LR. Testosterone treatment in adolescent boys with constitutional delay in growth and development. N Engl $\mathcal{f}$ Med 1988;319:1563-7.

9 Tanner JM, Whitehouse RH. Standards for sitting height and subischial leg length from birth to maturity; British children 1978. Hertford: Castlemead Publications, 1979.

10 Tanner JM, Whitehouse RH. Clinical longitudinal standards for height, weight, height velocity, weight velocity and for height, weight, height velocity, weight velocity
stages of puberty. Arch Dis Child 1976;51:170-9.

11 Tanner JM, Whitehouse RH, Cameron N, Marshall WA, Healy MJR, Goldstein H. Assessment of skeletal maturity and Healy MJR, Goldstein H. Assessment of skeletal maturity and
prediction of adult height (TW2 method). London: Academic prediction of adul

12 Ryden MB. An adult version of the Coopersmith self-esteem inventory: test-retest reliability and social desirability. Psychol Rep 1978;43:1189-90

13 LaFranchi SH, Hanna CE, Mandel SH. Constitutional growth delay: expected versus final adult height. Horm Res 1989;31:A67.

14 Volta C, Ghizzoni L, Buono T, Ferrari F, Virdis R, Bernasconi $S$. Final height in a group of untreated children with constitutional growth delay. Helv Paediatr Acta 1988;43:171-6.

15 Shalet SM, Gibson B, Swindell R, Pearson D. Effect of spinal irradiation on growth Arch Dis Child 1987;62:461-4.

16 Duke PM, Carlsmith JM, Jennings D, et al. Educationa correlates of early and late sexual maturation in adolescence. f Pediatr 1982;100:633-7. 